\title{
Real Time Simulation of Wind Farm Connected MMC-HVDC System
}

\author{
Naini Raju Manchala, Sreedevi J, Rajashekar P Mandi, Meera K.S
}

\begin{abstract}
Real time simulators play a major role in $R \& D$ of Offshore wind farm connected modular multilevel converter (MMC)-HVDC system. These simulators are used for testing the actual prototype of controllers or protection equipment required for the system under study. Modular multilevel converter comprises of number of sub modules (SMs) like Half/ full bridge cells. While computing time domain Electromagnetic transients (EMTs) with the system having large number of SMs pose a great challenge. This computational burden will be more when simulated in real time. To overcome this, several authors proposed equivalent mathematical model of MMC. This paper proposes the real time simulation start-up of offshore wind farm connected modular multilevel converter (MMC)-HVDC system. This paper also describes about how the above said systems is simulated in OPAL-RT based Hypersim software.
\end{abstract}

Keywords : Modular multilevel converter, Offshore wind farm, Real-time simulator, FPGA

\section{INTRODUCTION}

$\mathrm{O}_{\text {ver the years offshore wind farm planning has }}$ increased and the capacity is increasing day by day. Moreover, they are several miles away from onshore grids. Several offshore winds of capacities over 1000MW are planned in North Sea coast of Germany and Northwest coast of United Kingdom [1]. There was always a heated argument between DC and AC proponents over the years. The advantages like long distance bulk power transmission, long distance under water cable crossings, connecting two different frequency systems and power transfer through long distance underground cables make HVDC more popular than HVAC transmission [2].

Several authors in the literature described about the start-up sequence of MMC-HVDC technology [3]-[4]. No author in the literature described about simulation start up sequence of offshore wind farm connected MMC-HVDC system.

Revised Manuscript Received on March 5, 2020.

Naini Raju M, Senior Research Fellow, CPRI, Bengaluru

Smt. J Sreedevi, Joint Director, Power Systems Division (PSD), CPRI, Bengaluru.

Dr. Rajashekar P. Mandi, Director, School of Electrical and Electronics Engineering, REVA University,

Meera K S, Addional Director, Power System Division (PSD), CPRI, Bangalore.
Full scale modeling of MMC-HVDC with hundreds of SMs in per arm/valve as shown in Fig.1 is computationally immense talk, as it requires CPUs with high computing power and memory [2]. Detailed models which replicate the IGBT and its anti-parallel diode conductions are

inefficient as the time required for simulation is prohibitively long. To overcome this, several authors proposed equivalent model which replicate the actual MMC. Authors in [5][6] proposed average value model. This model assumes that all the capacitors in each SM are balanced and also assume an equivalent capacitor which replaces all the SM capacitors of the valve. One of the drawbacks of this model is that it cannot replicate the actual inner dynamics of MMC to the microscopic level. In [7][8] authors used Norton equivalent of valve in order to achieve real-time performance with reduced computational burden. In [9], IGBT switch is represented as resistance and capacitor as current source with conductance in parallel to it.

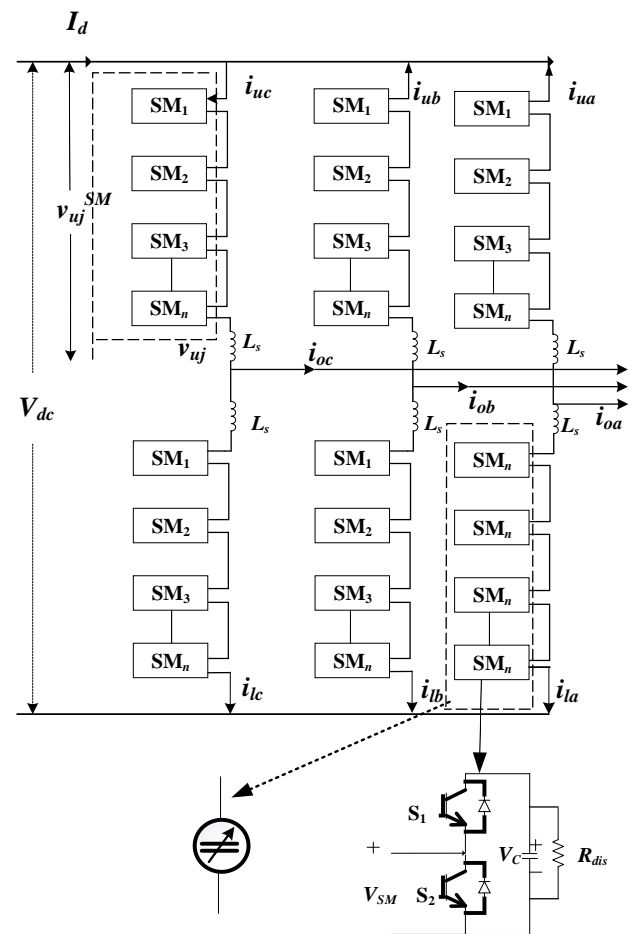

Fig. 1.MMC configuration

Authors in [10] proposed state space nodal method. The network under study is decoupled into system using nodal equations and such systems are solved using state space equations. In [11] authors proposed a surrogate network equivalent for each valve for both HB-SM and FB-SM separately. According to the switching states the SMs are divided into three sections (Blocked, Unblocked and Bypassed SMs) and a Thevenin's equivalent is used for each 
SM capacitor. Both Thevenin's and Norton's equivalent of the large electrical circuits still require huge computationalpower in order to recalculate to solve for every change of state of switches

In this paper an equivalent circuit proposed by authors in [12] is considered. Every detail of all the SMs in MMC are considered in this method and using Euler integration, it directly calculates the individual SMs capacitor voltages in parallel. As this method uses an equivalent circuit with certain topology it requires very less computational burden when compared to Thevenin's and Norton equivalents. This method can be implemented for HB-SM, FB-SM and other SMs like Double clamped SMs.

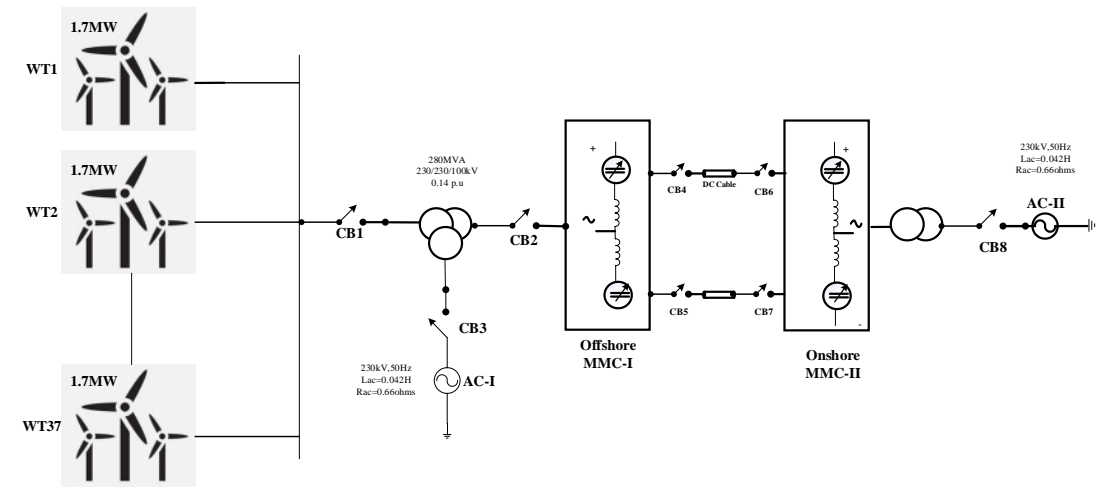

Fig. 2. Wind farm connected MMC-HVDC system

\section{II. . BASIC STRUCTURE OF OWF CONNECTED MMC-HVDC SYSTEM}

The SLD (single line diagram) of OWF connected MMC-HVDC system is shown in Fig .2. Wind turbine driven DFIG is considered for this study and modelling of DFIG is described in detail in the literature [13]- [16]. Each wind turbine connected DFIG has capacity to generate 1.7MW and 37 number of such DFIGs constitute Offshore Wind farm. Modelling of MMC-HVDC is explained in detail in the following sections. Parameters of MMC-HVDC systems are given in Table. 1

Table-I.Main circuit parameters

\begin{tabular}{|l|l|}
\hline \multicolumn{1}{|c|}{ Circuit components } & \multicolumn{1}{c|}{ Parameters } \\
\hline AC system voltage (AC-I\&AC-II) & $230 \mathrm{kV}$ \\
\hline AC system inductance (AC-I\&AC-II) & $0.04 \mathrm{H}$ \\
\hline AC system resistance (AC-I\&AC-II) & $0.64 \mathrm{ohm}$ \\
\hline Tertiary Transformer rating & $100 \mathrm{MVA}$ \\
\hline Tertiary Transformer ratio & $230 / 230 / 100 \mathrm{kV}$ \\
\hline Tertiary Transformer leakage reactance & $18 \%$ \\
\hline DC bus voltage & $+/-100 \mathrm{kV}$ \\
\hline Equivalent arm resistance $R s$ & $0 \mathrm{ohms}$ \\
\hline Number of SMs per arm N & 250 \\
\hline SM Capacitance & $24 \mathrm{mF}$ \\
\hline Arm inductance $L s$ & $0.0024 \mathrm{H}$ \\
\hline
\end{tabular}

\section{A. Opearating principle and topology of MMC}

Modular multilevel converter consists of $\mathrm{N}$ number of SMs. Each SM can be half bridge/ full bridge or any other converter cells. Half bridge can generate two level output voltage and full bridge SM can generate three level output voltage. All the SMs are connected in series in each arm along with arm reactor $L s$ as shown in Fig. 1.

A half bridge SM is considered for present study and can be seen in Fig. 1. In normal operation each HB-SM has three states: First is Blocked state where both switches are OFF (and) and Second is Inserted state where $V_{S M}=V c$ (when switch $S_{1}$ is $O N$ and $S_{2}$ is OFF) and Third state is Bypassed state where $V_{S M}=0$ (When switch $\mathrm{S} 1$ is OFF and switch $\mathrm{S} 2$ is $\mathrm{ON})$. Capacitor voltage of SM is set and can be controlled to its nominal value in normal operating condition. Then, the per-unitized total voltage across the arm is nothing but the voltage across the SMs which are ON. With this we can conclude that each arm can be an equivalent controllable voltage source like in the case of voltage source converters.

\section{B. Modelling of SubModule in FPGA}

Mathematical modelling of each SM is carried out in Field programmable gate array (FPGA) at discrete fixed time step. $V_{C}$ represents the voltage of capacitor in each SM, which is nothing but the discrete integral of charging current through the capacitor represented by $\mathrm{iC}$. as depicted in Eq.1. Here the values (n-1) and $n$ represent the previous step value and the present step value respectively and $\Delta T_{\text {fpga }}$ represents FPGA time step (500ns for this particular study) and SM capacitance is represented by $C$.

$V_{C . n}=V_{C .(n-1)}+\frac{\Delta T_{f p g a}}{C_{S M}} \times i_{C . n}$

$i_{C . n}=K \times i_{a m}-\frac{V_{C .(n-1)}}{R_{d i s}}$

$V_{S M}=K \times V_{C . n}-i_{a m . n} \times R_{o n}$

The charging current of the capacitor is obtained as shown in Eq.2. Where K represents the state of the upper switch in SM and arm current is represented by $i_{a m}$. The arm current fill flow through the upper arm when the switching state $K=1$ and passes through the capacitor and the discharge resistance connected parallel to it $\left(R_{d i s}\right)$. Otherwise the lower switch in SM will bypass the arm current. Forward Euler integration method is used where the capacitor voltage in the previous state is used to break the algebraic loop. The error introduced due to method is negligible as the time step consider is much smaller than the voltage discharge time constant of the capacitor. Lastly the SM voltage is obtained as shown in Eq. 3 and it is represented by $V_{S M}$ and conduction losses of the IGBT switches represented with resistive losses as internal resistance is represented as $R_{O N}$.

Modelling of SM in FPGA is shown in Fig. 3. Here it can be observed that IGBT switching state and the arm currents 
are the inputs to the SMs in FPGA and total SMs voltage at the terminal is the output from FPGA. Capacitor voltage of each SM is the internal state and remaining parameters are all known. With the use of base power and nominal voltage of $\mathrm{SM}$, all the parameters are converted into per unit values using nominal voltage and power of SMs as base values. FPGA has capability of larger parallel operating units. For the present study, the bit stream used has the capability of solving 1530 SMs at 500ns time step in one FPGA unit. MMC with larger number of SMs like more than 500 SMs per arm which means 3000 SMs and more for both converters can be solved in two FPGA Virtex-7 and Virtex-6 boards.

\section{Decoupling and Simualition at Mutli rate}

The voltage across all the SMs in one arm is the defined as output voltage of MMC as depicted in Eq.3.

The second term in this equation is insignificant (as resistance under conducting state is small) and the first term is predominant. Moreover, due to presence of arm reactor, the arm current cannot change abruptly. Due to this reason, the arm current from the previous time can be utilised for finding the total SM capacitor voltage as shown in Eq.3.Thus, the output voltage of MMC is obtained mainly by switching states and voltage of capacitor in each SM. These capacitor voltages are non-other than those defined by the historic values in the internal states. This is how the SMs of each arm in MMC can be evaluated separately in FPGA and is also decoupled for the rest of system.

Simulation of whole system is carried out at different sampling rates. Mathematical modelling of MMC is carried out in FPGA as demonstrated in previous at sampling time of $500 \mathrm{~ns}$ and the rest of the systems including DFIG based wind farms is simulated in CPU at sampling time of 30micro seconds. Here in the CPU the MMC is represented as a controllable equivalent voltage source.

The FPGA and CPU have to be synchronized; the exchange of data occurs at sampling time of CPU. This is because the data present in the FPGA updates at faster rate than compared to the CPU. Express link PCIe will act as channel for the transfer of data from CPU to FPGA and vice versa. FPGA send output terminal voltage to the CPU and CPU will send arms current in turn to FPGA. Due to arm reactor, the arm current changes gradually and is transferred from CPU to FPGA at the instant of synchronization (instantaneous value at the instant of sync). Until the next sync instant, it is held for one-time step of CPU.

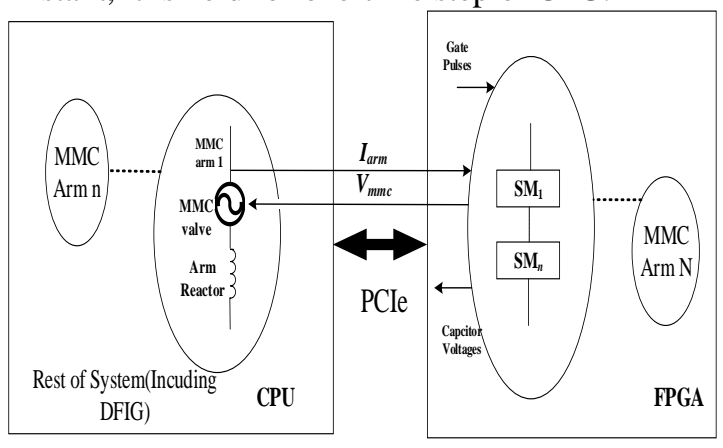

Fig. 3. FPGA and CPU simulation at Multi rate

The output terminal voltage of MMC is updated in FPGA after parallel processing at a faster rate. Due to inter step switching events there may be many step changes within each CPU time step. It is not advisable to transfer instantaneous value of the output voltage of MMC at every CPU time sampling which may lead to inaccurate results due to problem of aliasing at poor sampling of signal (at CPU time step).The arm current mainly depends on arm reactor but have accurate results as it is required to send average value of the MMC output voltages calculated within FPGA to CPU over the time period of CPU time step

\section{CONTROL STRUCTURE OF MMC}

The overall control structure of MMC is given in Fig. 4. Multilevel voltage signals are achieved by comparing the sinusoidal reference signal with many carrier singles and the process is called pulse width modulation (PWM). Phase shifted carrier PWM modulation technique is utilized for generation of gate pulses.

The reference sinusoidal signal $n_{i}$ consists of both DC component and sinusoidal fundamental component whereas in the frequency domain, the synthesized multilevel signal $\mathrm{Ni}$ after PWM consists of components as shown in Eq.4.

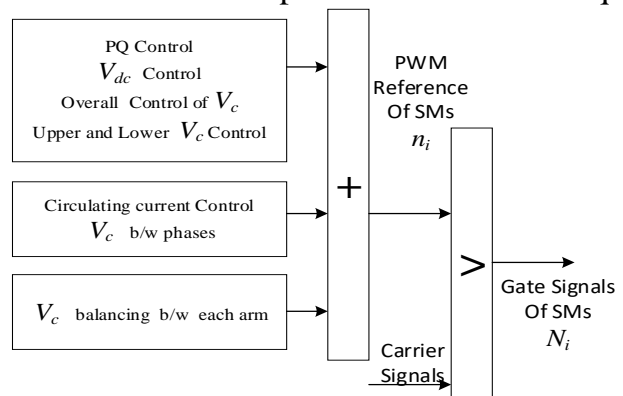

Fig. 4. Control structure of MMC $N_{1 i}=n_{1 i}+$ harmonics

Fig. 4. shows the overall control structure required for the normal operation of MMC and the SM capacitor voltage balancing control scheme is one among them. SM capacitor voltage balancing control scheme is described in detail in [17]

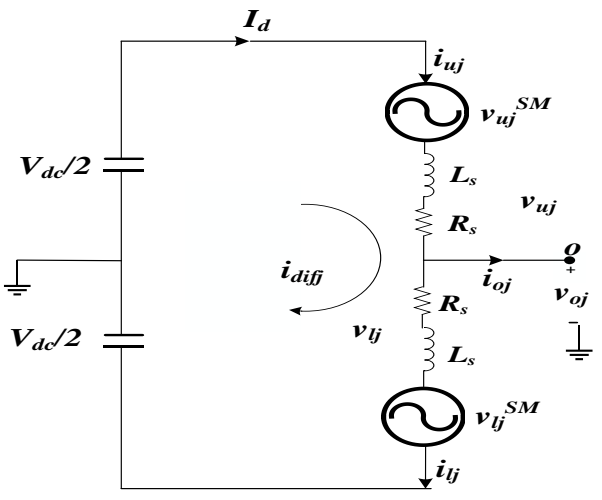

Fig. 5.MMC single phase equivalent

A single-phase equivalent of MMC is shown in Fig. 5 where $R_{s}$ and $L_{s}$ are arm resistance and inductance respectively. $V_{d c}$ and $I_{d}$ are the 'dc' voltage and current respectively. $v_{o j}$ is the converter 'ac' output voltage of $j$ phase and $i_{o j}$ is corresponding 'ac' line current of phase $j . v_{l j}^{S M}$ and $v_{u j}^{S M}$ represent the converter 
arm voltage which is generated by total voltage across the SMs of lower and upper arms respectively of phase $j$.From Fig. 5, the lower arm current $i_{l_{j}}$ and upper arm current $i_{u_{j}}$ can be expressed in terms of difference currents $i_{d i f_{j}}$ and 'ac' line current of the corresponding phase as shown in Eq.1 and 2.

$i_{u_{j}}=i_{d i f_{j}}+\frac{i_{o_{j}}}{2}$

$i_{l_{j}}=i_{d i f_{j}}-\frac{i_{o_{j}}}{2} \quad$ (where $\left.j=a, b, c\right)$

In each phase the inner current of each phase flows through lower and upper arms is shown in Eq.6.

$i_{d i f_{j}}=\frac{i_{u_{j}}+i_{l_{j}}}{2}$

From Fig. 5, the following equations of MMC can be characterized as

$v_{o_{j}}=v_{j}-\frac{R_{s}}{2}+i_{o_{j}}-L_{s} \frac{d i_{o_{j}}}{2}$

$L_{s} \frac{d i_{d i f_{j}}}{d t}+R_{s} \times i_{d i f_{j}}=\frac{V_{d c}}{2}-\frac{v_{l j}^{S M}+v_{u j}^{S M}}{2}$

Where $v_{j}$ is called the inner EMF generated in phase $\mathrm{j}$ and is expressed as of upper and lower arm voltages generated by cascaded SMs.

$v_{j}=\frac{v_{l j}^{S M}-v_{u j}^{S M}}{2}$

Here $v_{o_{j}}$ is considered as 'ac' voltage and $i_{o_{j}}$ as 'ac' current of phase $j$ and the control variable $v_{j}$ can control $i_{o_{j}}$. The current control scheme proposed by many authors earlier can be adopted for MMC and Eq. 9 determines the MMC inner dynamic performance and can be redefined as

$$
v_{d i f_{j}}=L_{s} \frac{d i_{d i f_{j}}}{d t}+R_{S} \times i_{d i f_{j}}=\frac{V_{d c}}{2}-\frac{v_{l j}^{S M}+v_{u j}^{S M}}{2}
$$

Where $v_{d i f_{j}}$ is called inner unbalance voltage of respective phase.

Modular multilevel converter configuration with its unique feature requires additional controls apart from basic controls of Voltage source converters (Active and reactive power control). All the multiple control schemes of MMC are classified as Active and Reactive power control, DC voltage control scheme, SM capacitor voltage control (Balancing among each SM and Overall SM control) and Circulating current suppression control.

\section{A. Reactive and Active power Control scheme}

The basic control scheme for MMC is similar to conventional $d q$ control of VSC. Where the ac voltage of VSC is controlled to the reference value which is recalculated so that both reactive and active powers tract the actual set points as shown in Fig. 6. The actual control logic is described in [18]. The voltage across the upper and the lower arm phase reactors $v_{u_{j}}$ and $v_{l_{j}}$ are controlled as per the same reference value of the control loop, then the lower and the upper arm equally contribute to the phase currents.

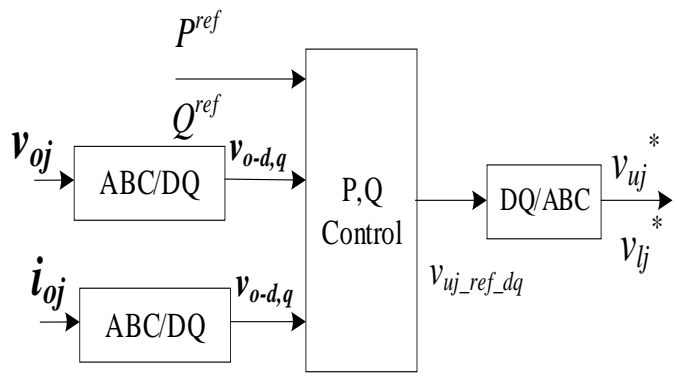

Fig. 6. Reactive and Active power control

\section{B. DC link voltage control}

In Static VAR compensator (SVC) the DC capacitor voltage determines the DC voltage and is regulated with active power control scheme. But in case of DC voltage control in MMC is direct and fast using separate control scheme while neglecting DC capacitor link. DC voltage is determined by the following equations form Fig.7.

$V_{d c}=v_{l j}^{S M}+v_{u j}^{S M}+v_{u_{j}}+v_{l_{j}}$

In order to regulate DC voltage $\left(V_{d c}\right)$ to $1 \mathrm{pu}$, the gating pulse of $\mathrm{SM} N_{1 i}$ is calculated as shown in Fig. 7and also the reference PWM signals $n_{1 i}$ are calculated.



Fig. 7.DC link voltage control

\section{Circulating current suppression control scheme}

The main cause for the generation of circulating current is the difference among the voltages of each phase in MMC which was observed by authors in [19]-[20]. These circulating currents are basically negative sequence current with frequency twice than that of fundamental [22]. This leads to increase in the rms value of arm current which in-turn results in increase of converter power losses [19]. In each phase these circulating currents get super imposed on the 'dc' current component [22]. As a result of all the above discussion, it can be concluded that inner difference current described in Eq.3 that consists of two parts. One is the 'ac' component corresponding to circulating current and the other is the 'dc' current component (One-third of complete 'dc' current component). Unbalanced inner voltages and currents are transformed to $d q$ reference frame using ABC/DQ transformation and Fig. 8 depicts the circulating current transfer function.

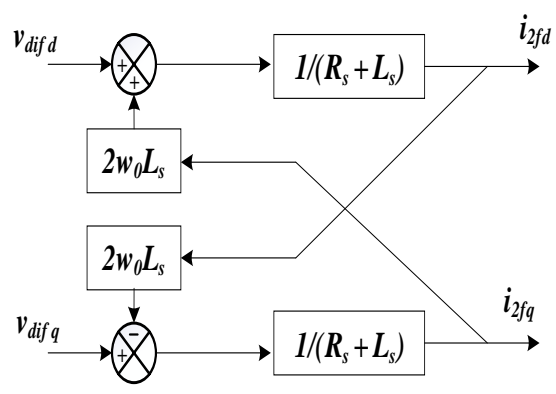

Fig. 8. Circulating currents transfer function

In order to minimize the circulating current, reference value of both circulating currents in 'dq' reference are set to zero i.e., $i_{2 f_{d_{r e f}}}=0$ and $i_{2 f_{q_{r e f}}}=0$. With cross coupling 
compensationandPIcontroller,

the

control signals $v_{d i f_{d_{-} r e f}}$ and $v_{d i f_{q_{-} r e f}}$ are obtainedas shown in Fig. 9. Finally, the unbalance inner difference voltage in ' $a-c-b$ ' reference frame is obtained using inner transformation matrix.



Fig. 9.Circulating current suppression control scheme

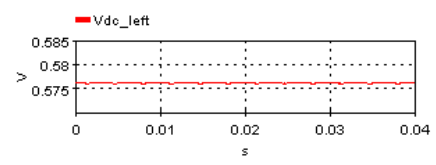

(a)


(b)
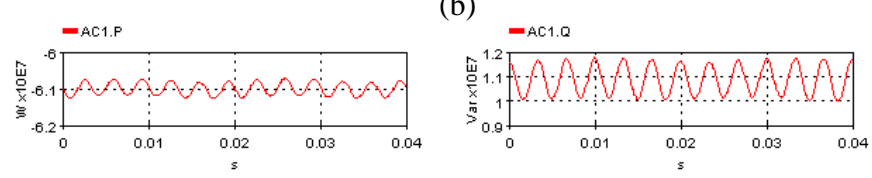

(c)
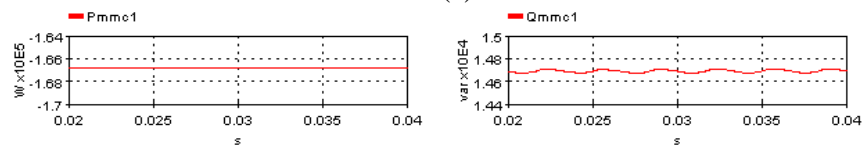

(d)
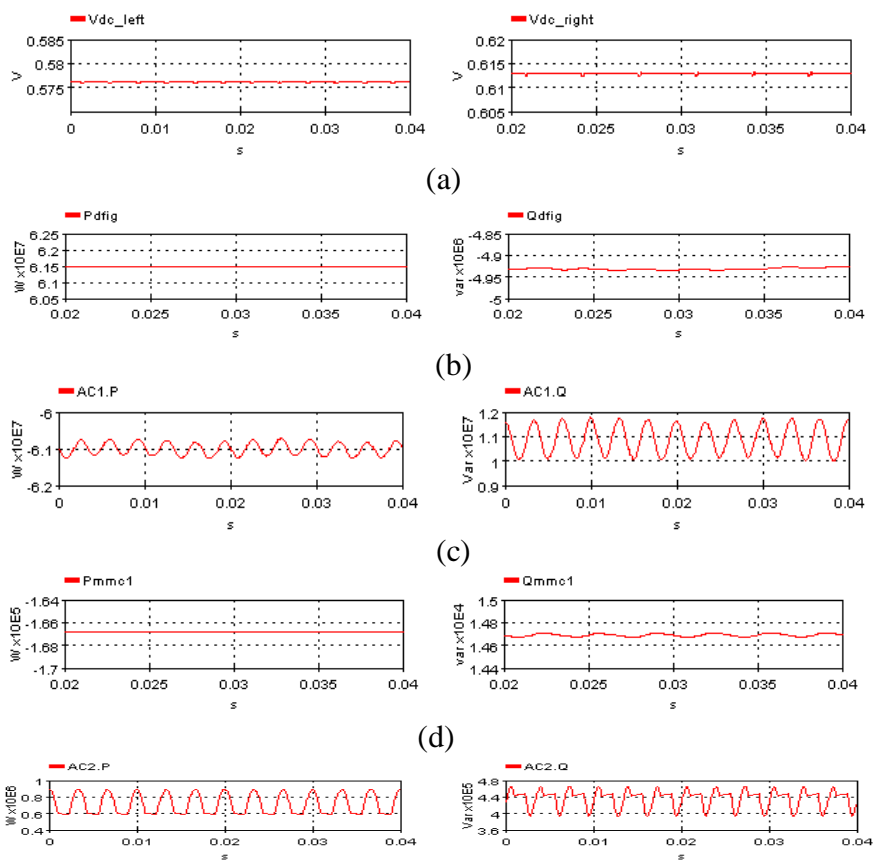

The start-up sequence of MMC-HVDC connected Offshore wind is a bit complex as the all the SM capacitors need to be charged to certain level before evacuating power generatedby windfarm through $\mathrm{HVDC}$ link. Initially $\mathrm{CB}_{1}$ and $\mathrm{CB}_{3}$ are closed (also $\mathrm{CB}_{2}, \mathrm{CB}_{8}$ and all $\mathrm{DC}$ breakers are open)as all the windfarms are energized and the power generated from these windfarms can be seen as $\mathrm{P}_{\mathrm{ac} 1}$ and $\mathrm{Q}_{\mathrm{ac} 1}$ in Fig. 10(c). Per unit voltage in the DC link are charged to $0.576 \mathrm{pu}$ on left and $0.61 \mathrm{pu}$ on right as shown in Fig. 10(a) at this stage as the $\mathrm{AC}$ breakers $\mathrm{CB}_{2}$ and $\mathrm{CB}_{8}$ are open. Fig.10(b) depicts the real and reactive power flow at the point of common coupling(PCC) where DFIG is connected to MMC-HVDC link. Fig. 10(d) presents the real and reactive power entering the Offshore MMC converter. $I_{\text {arm. }}$.

(e)

Fig. 10. Simulation results before uncontrolled charging (a) DC voltage in PU on near MMC-I\&II. (b)Real and reactive power generated by DFIG. (c). (d) Real and reactive entering MMC-1 (e)Real and reactive AC-II

\section{A. Uncontrolled charging of SM capacitors from AC grid}

As the second stage of start-up sequence of offshore wind farm connected MMC-HVDC systems, the $\mathrm{CB}_{2}$ and $\mathrm{CB}_{8}$ are

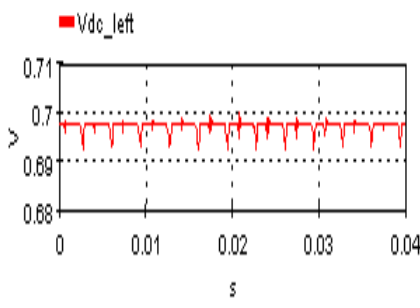

Fig. 11. DC voltage in PU on near MMC-I\&II after uncontrolled charging.

\section{B. Controlled charging of SM capacitors from AC grid}

After the dc link voltages are charged to 0.7 pu unit, the IGBT pulses of both onshore and offshore converters are enabled. This results in both the DC link voltages are closed. Immediately after closing these ac circuit breakers, it is observed from the Fig. 11 that the pu voltage of the DC link on the left and the right are charged to around $0.7 \mathrm{pu}$.



charged to $1 \mathrm{PU}$ as shown in Fig.12. As both the DC breakers are open $\left(\mathrm{CB}_{4}-\mathrm{CB}_{7}\right)$ both the converters operate in STATCOM mode. 



Fig. 12. DC voltage in PU on near MMC-I\&II after controlled charging.

\section{Power Evacuation through HVDC link with PQ} control and disconnecting offshore $\mathrm{AC}$ grid

One of the major advantages of MMC is that both active and reactive power can be controlled independently. After the pulse signal of both offshore and onshore grid are enabled, Voltage of the DC link will attain 1 pu(STATCOM mode of operation) and later the DC breakers are closed. Active power control enables the flow of real power in both the direction (Mode of operation of MMC as inverter/converter which will depend on the active power control). Keeping this in view active power control isset in such a way that the Offshore MMC will act as rectifier and onshore will act as

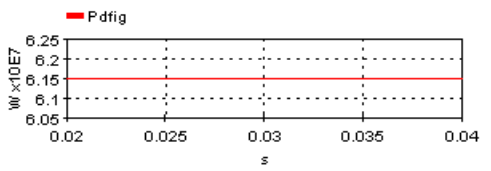

(a)

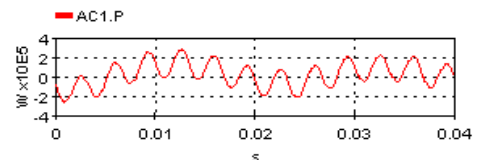

(b)

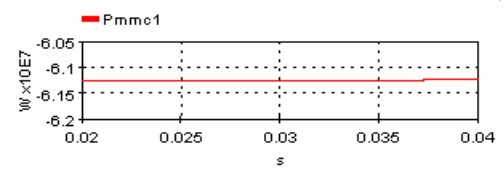

(c)

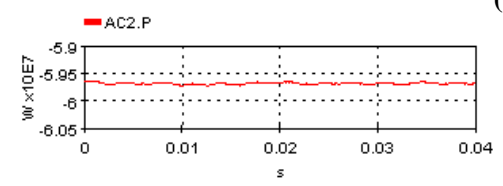

(d)

Fig. 13. Simulation results after disconnecting AC-1 (a) DC voltage in PU on near MMC-I\&II. (b) Real and reactive power generated by DFIG. (c) Real and reactive power entering MMC-1 (d) Real and reactive power in AC-II

\section{CONCLUSION}

Modular multilevel converter comprises of number of sub modules (SMs) like Half/ full bridge cells. While computing time domain Electromagnetic transients (EMTs) with the system having large number of SMs pose a great challenge. To overcome challenge this paper need for real time simulation and also proposed the real time simulation of offshore wind connected MMC-HVDC system and its startup sequence. This paper also describes about the mathematical modelling of MMC in CPU and FPGA and multi rate sampling and its advantages are also explained in detail. Thecontrol architecture of MMC and its necessity is explained in detail. The start up sequence of the wind farm connected MMC-HVDC system is explained.
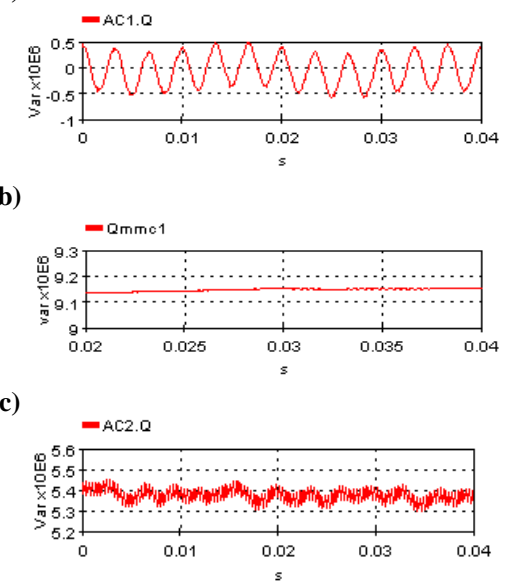

inverter. Both the converters can either supply reactive power orabsorb reactive as per the requirement.

In the present scenario, the active power control is set in such a way that the total power generated by the windfarms is evacuated through HVDC link and the power observed by AC-1 (both active and reactive power) is zero as shown in Fig. 13(b). At this instant angle in phase locked loop(PLL) is adjusted and CB3 is opened to disconnect AC source (AC-I). From Fig. 13, it can be observed that the real power received at $\mathrm{AC}-\mathrm{II}$ is $59.5 \mathrm{MW}$ and the negative sign indicates the real powerabsorption.

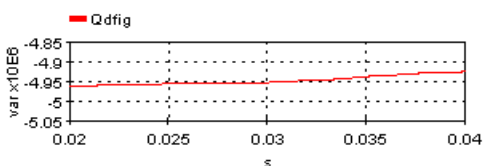

(a)

\section{REFERENCES}

1. S. V. Bozhko, et al, "Control of Offshore DFIG-Based Wind Farm Grid With Line-Commutated HVDC Connection," IEEE Transactions on Energy Conversion, vol. 22, no. 1, pp.71-78, March 2007.

2. M. N. Raju, J. Sreedevi, R. P Mandi and K. S. Meera, "Modular multilevel converters technology: a comprehensive study on its topologies, modelling, control and applications," in IET Power Electronics, vol. 12, no. 2, pp. 149-169, 2022019.

3. Fanqiang Gao, Zixin Li, Fei Xu, Zunfang Chu, Ping Wang and Yaohua $\mathrm{Li}$, "Startup strategy of VSC-HVDC system based on modular multilevel converter," in Proc. of Energy Conversion Congress and Exposition, ECCE 2014, Pittsburg, PA, USA, Sept. 2014.

4. S. Dennetiere, S. Nguefeu, H. Saad and J. Mahseredjian, "Modeling of Modular Multilevel Converters for the France-Spain link," in Proc. of Int. Conf. on Power System Transients, IPST 2013, Vancouver, Canada, July 2013. 
5. O. Venjakob, S. Kubera, R. Hibberts-Caswell, P.A. Forsyth, T.L. Maguire, "Setup and Performance of the Real-Time Simulator used for Hardwarein- Loop-Tests of a VSC-Based HVDC scheme for Offshore Applications", Proceedings of International Conference on PowerSystems Transients (IPST'13), Vancouver, Canada, July 18-20, 2013.

6. N. Ahmed, L. Ängquist, S. Norrga, H.-P. Nee, "Validation of the continuous model of the modular multilevel converter with blocking/deblocking capability," 10th IET International Conference on AC and DC Power Transmission (ACDC 2012), 6 pp., 2012.

7. P. Le-Huy, P. Giroux, J.-C. Soumagne, "Real-Time Simulation of Modular Multilevel Converters for Network Integration Studies,"International Conference on Power Systems Transients, Delft, Netherlands June 14-17, 2011.

8. U. N. Gnanarathna, A. M. Gole, and R. P. Jayasinghe, “ Efficient Modeling of Modular Multilevel HVDC Converters (MMC) onElectromagnetic Transient Simulation Programs," IEEE Trans. Power Del., vol. 26, no. 1, pp. 316-324, Jan. 2011.

9. H. W. Dommel, "Digital computation of electromagnetic transients in single and multi-phase networks," IEEE Trans. Power App. Syst., vol. PAS-88, no. 4, pp. 388-399, Apr. 1969.

10. C. Dufour, J., Mahseredjian, J., Belanger, "A Combined State-Space Nodal Method for the Simulation of Power System Transients", IEEETransactions on Power Delivery, vol. 26, no, 2, pp. 928-935, 2011.

11. T. L. Maguire, B. Warkentin, Y. Chen, and J. Hasler, "Efficient Techniques for Real Time Simulation of MMC System", Proceedings ofInternational Conference on Power Systems Transients (IPST'13), Vancouver, Canada, July 18-20, 2013

12. W. Li and J. Bélanger, "An Equivalent Circuit Method for Modelling and Simulation of Modular Multilevel Converters in Real-Time HIL T

13. R. Pena, J. C. Clare and G. M. Asher, "Doubly fed induction generator using back-to-back PWM converters and its application to variable-speed wind-energy generation," in IEE Proceedings - Electric Power Applications, vol. 143, no. 3, pp. 231-241, May 1996.

14. Siegfried Heier, $<<$ grid integration of wind energy conversion systems >>, john wiley\& sons, 1998,ISBN 0-471-97143-X

15. Nicholas W. Miller, Juan J.Sanchez-gasca,WilliamW.Price,Robert W. Delmerico "Dynamic modelling of FG 1.5 and 3.6 MW wind turbine generator for stability simulation". GE Power Sytems Energy Consulting, IEEE WTG Modeling Pane,Session July 2003.

16. Nicholas W. Miller, Juan J.Sanchez-gasca, Dynamic modelling of FG 1.5 and 3.6 MW wind turbine generator" GE GE Power Sytems Energy Consultin, Version 3.0.October 272003.

17. Wei Li, L-A Gregoire, J. Bélanger, "Control and Performance of a Modular Multilevel Converter System," in Proc. of CIGRE, Canada,

18. W. Li and G. Joós, "A power electronic interface for a battery supercapacitor hybrid energy storage system for wind applications," in Proc. 2008 IEEE Power Electronics Specialists Conference (PESC), pp. $1762-1768$.

19. A. Antonopoulos, L. Angquist, and H. P. Nee, "On dynamics and voltage control of the modular multilevel converter," in Proc. Eur. Conf. Power Electron. Appl., Barcelona, Spain, 2009, pp. 1-10.

20. Q. Tu, Z. Xu, H. Huang, and J. Zhang, "Parameter design principle of the arm inductor in modular multilevel converter based HVDC," in Proc. Int. Conf. Power Syst. Technol., Hangzhou, China, 2010, pp.

\section{AUTHORS PROFILE}

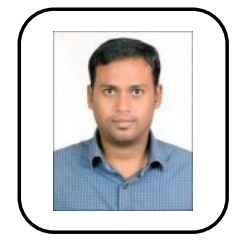

Naini Raju M received the B-Tech degree in electrica and electronics engineering from KL University, Guntur, AP,INDIA, in 2009, and has M-Tech degree from JNTU Karimnagar, Telangana, INDIA Currently, working as Senior Research Fellow at CPRI, Bengaluru and is pursuing the Ph.D. degree in electrical engineering VTU Belgaum. His research interests include CPU/FPGA based real-time computations, power electronics and renewable energy integration.

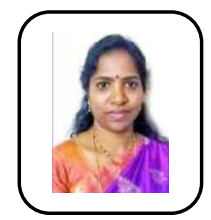

Smt. J Sreedevi ,Joint Director, Power Systems Division (PSD), CPRI, Bengaluru. She completed graduation in Electricals \& Electronics Engineering from Sri Venkateswara University, Tirupati, India in 1991 and post-graduation in System Science and Automation from IISc Bengaluru in 1994. She has rendered consultancy services for various utilities and industries in areas of Power system modelling and simulation. Her research interests include real time digital simulation studies of FACTS and HVDC controllers.

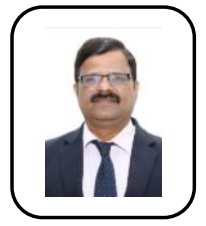

Dr. Rajashekar P. Mandi, Director, School of Electrical and Electronics Engineering, REVA University, holds Doctorate from NITK, Surathkal in the area of "Power and Energy" and holds M. Tech. degree with 3rd Rank in "Energy Systems Engineering" from BV Bhoomaraddi College of Engineering \& Technology, Hubli of Visveswaraiah Technology University (VTU), Belgaum. He also obtained Master of Computer Application (MCA) degree from IGNOU, New Delhi. His research interests include smart grid, microgrid, LVDC, hybrid power system, renewable energy systems, energy conservation, strengthening of electrical distribution systems, electrical safety, power quality, LED lighting systems, etc. Presently he is guiding $8 \mathrm{PhD}$ research scholars, guided $15 \mathrm{MTech}$ Projects and 15 BTech. Projects. He had written 3 book chapters on energy conservation in Thermal Power plants and 2 book chapters in distributed power generation. $\mathrm{He}$ had published more than 141 technical papers in International \& Indian Journals, Conferences \& Seminars in the field of energy conservation, power quality, LED lighting system and renewable energy systems.

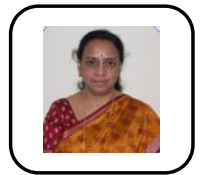

Meera K S, Addional Director, Power System Division (PSD), CPRI, Bangalore. She has been working in CPRI for the last 32 years \& having an expertise in the areas of modelling and simulation of power systems for transmission planning studies, system operation and control, simulation using Real Time Digital Simulator (RTDS), Protection System studies and Grid integra on of renewables. Her research areas FACTS controllers \& renewables and synchro-phasor application on to power systems. 